\title{
Chorionic Gonadotropin- $\beta$ Modulates Epithelial-Mesenchymal Transition in Colorectal Carcinoma Metastasis
}

Futoshi Kawamata, ${ }^{*}$ Hiroshi Nishihara, ${ }^{\dagger}$ Shigenori Homma, ${ }^{*}$ Yasutaka Kato,${ }^{\ddagger}$ Masumi Tsuda, ${ }^{\ddagger}$ Yuji Konishi, ${ }^{*}$ Lei Wang, Shinji Kohsaka, ${ }^{\S}$ Cheng Liu, ${ }^{\top}$ Tadashi Yoshida, ${ }^{*}$ Mishie Tanino, ${ }^{\ddagger}$ Shinya Tanaka, ${ }^{\ddagger}$ Hideki Kawamura, ${ }^{*}$ Toshiya Kamiyama, ${ }^{*}$ and Akinobu Taketomi*

From the Departments of Gastroenterological Surgery I, ${ }^{*}$ Translational Pathology, ${ }^{\dagger}$ and Cancer Pathology, ${ }^{\ddagger}$ Hokkaido University Graduate School of Medicine, Sapporo, Japan; the Department of Cellular Signaling, ${ }^{\S}$ Graduate School of Medicine, University of Tokyo, Tokyo, Japan; and the Conjoint Gastroenterology Laboratory," QIMR Berghofer Medical Research Institute, Brisbane, Queensland, Australia

Accepted for publication August 28, 2017.

Address correspondence to Hiroshi Nishihara, M.D., Ph.D., Department of Translational Pathology, Hokkaido University Graduate School of Medicine, Kita-ku, Kita 14, Nishi 7, Sapporo 060-8638, Japan. Email: hnishihara@s5.dion.ne.jp.
Ectopic production of free $\beta$ human chorionic gonadotropin (hCG $\beta$ ) has been associated with aggressive behavior in non-trophoblastic tumors. hCG $\beta$ shares common evolutionary sequences with transforming growth factor- $\beta$ (TGF- $\beta$ ), which represents a major driving force of epithelial-to-mesenchymal transition (EMT). In this study, we examined the biological roles of hCG $\beta$ during EMT and its clinical significance in colorectal cancer (CRC) progression. Eighty CRC specimens and 54 preoperative serum samples were analyzed. hCG $\beta$-overexpressing human CRC cell lines were examined for invasiveness and tumorigenicity, and the expression of EMT-associated genes was investigated. In human CRC, histologic hCG $\beta$ positivity $[13 / 80(16.3 \%)]$ was lower than serologic hCG $\beta$ positivity $[13 / 54(24.1 \%)]$. However, it was significantly correlated with several clinicopathological features and unfavorable outcome $(P<0.05)$. hCG $\beta$-overexpressing cell lines had increased invasiveness, migratory ability, and metastatic potential in mice $(P<0.01)$. Western blot, PCR, and microarray analyses showed hCG $\beta$ altered expression of EMT-related genes, including E-cadherin, phosphorylated SMAD2, SNAIL, and TWIST. hCG $\beta$-induced SNAIL and TWIST overexpression levels were reversible by type I and type II TGF- $\beta$ receptor inhibitors $(P<0.05)$. hCG $\beta$ thus induces EMT via the TGF- $\beta$ signaling pathway, and it may represent a molecular target in CRC treatment. (Am J Pathol 2018, 188: 204-215; https://doi.org/10.1016/j.ajpath.2017.08.034)
The incidence of colorectal cancer (CRC) is estimated at one million new cases per year worldwide, and this number has been increasing during the past 25 years. ${ }^{1,2}$ Although surgical resection combined with adjuvant therapy is an effective treatment at the early stage of this disease, subsequent relapse and metastasis often occur. At an advanced stage, resistance to conventional therapies is frequent and the existing treatments are ineffective. Therefore, a better understanding of the molecular mechanisms underlying the response to these drugs is crucial for the identification of new predictive biomarkers and the development of targeted treatments.

Human chorionic gonadotropin (hCG) is a glycoprotein hormone that consists of two polypeptide subunits $(\alpha$ and $\beta$ chains). ${ }^{3}$ Only the intact $\alpha-\beta$ heterodimer is hormonally functional. The $\beta$ subunit alone is not sufficient to stimulate the hCG receptor, and the intact heterodimer is required for both binding and subsequent generation of second messengers. ${ }^{4}$ hCG has traditionally been used as a marker for pregnancy, pregnancy-associated disorders, and gestational trophoblastic disease, but it is also secreted in nontrophoblastic malignancies, including colorectal, gastric, and pancreatic cancers. ${ }^{5-7}$ The ectopic production of free hCG $\beta$ in the absence of the $\alpha$ subunit is a well-recognized phenomenon in the aforementioned epithelial tumors. According to several reports, hCG $\beta$-secreting tumors are more

Supported by the Uehara Memorial Foundation Fellowship grant 201430015 (F.K.).

Disclosures: None declared. 
aggressive and radioresistant and have a greater propensity to metastasize. ${ }^{5,8}$ However, it remains unclear why hCG $\beta$ secreting tumors are associated with poor prognosis.

Interestingly, hCG $\beta$ shows significant homology with transforming growth factor- $\beta$ (TGF- $\beta$ ), ${ }^{9}$ a major driving molecule in epithelial-to-mesenchymal transition (EMT). The topological similarities observed, such as the identical cystine-knot motif, ${ }^{9}$ suggest that they may have similar receptor-mediated effects. However, the functional role of hCG $\beta$ during CRC tumorigenesis is yet to be characterized.

The objectives of this study were twofold. The first was to examine the prognostic impact of hCG $\beta$ in human CRC. The second was to further elucidate the role of $\mathrm{hCG} \beta$ in CRC development, notably its relationships with EMT and tumorigenic potential through the activation of the TGF- $\beta$ receptor. We designed a series of in vitro and in vivo experiments to this effect.

\section{Materials and Methods}

\section{Human Colorectal Cancer Tissue Samples}

This aspect of the study was performed with the approval of the Internal Review Board on Ethical Issues of Hokkaido University Hospital (Sapporo, Japan). Eighty patients with invasive CRC who underwent radical surgery at Hokkaido University Hospital between 2002 and 2004 were included in the study. Patients were followed up at 1- to 6-month intervals until death or December 31, 2015, whichever was earlier. Patient clinical features are shown in Supplemental Table S1.

\section{Pathologic and hCG $\beta$ Immunohistochemical Evaluation}

Formalin-fixed, paraffin-embedded blocks from the 80 patients were retrieved. One representative block containing invasive tumor was selected from each patient, and one section was cut and stained with hematoxylin and eosin for routine histopathological examination. Pathologic evaluation of primary tumor was performed according to the American Joint Committee on Cancer classification (edition 7). ${ }^{10}$ Other pathologic information (eg, lymph node status) was obtained from the original pathology report.

hCG $\beta$ immunohistochemistry (IHC) was performed on the same selected block for each patient. Briefly, after deparaffinization and rehydration, tissue sections were incubated with a rabbit polyclonal antibody against hCG $\beta$ (1:350; A0231; Dako, Tokyo, Japan), followed by reaction with a dextran polymer reagent combined with secondary antibodies and peroxidase (Envision/HRP; Dako, Tokyo, Japan). All assessments were made on viable tumor at $\times 400$ magnification. Each slide was evaluated independently by three pathologists (Y.K., C.L., and S.T.) who were blinded to clinical outcomes. Tumors with cytoplasmic staining of more than five epithelial cell clusters were considered hCG $\beta$ positive.

\section{Human Serum Samples and hCG $\beta$ Quantitation}

Of the 80 CRC patients, 54 had preoperative serum samples available for analysis. Serum levels of hCG $\beta$ were measured by an immunofluorometric assay, as described previously. ${ }^{5,11}$ Serological positivity was defined as $\geq 2 \mathrm{pmol} / \mathrm{L}$, as reported previously. ${ }^{5}$

\section{Cell Culture}

Five human CRC cell lines were used. Caco-2, LoVo, and HCA7 cell lines were cultured in Dulbecco's modified Eagle's medium supplemented with $10 \%$ fetal bovine serum, $100 \mathrm{IU} / \mathrm{mL}$ penicillin, and $100 \mathrm{mg} / \mathrm{mL}$ streptomycin (Life Technologies, Rockville, MD). The WiDr cell line was cultured in RPMI 1640 medium containing the same concentrations of fetal bovine serum and antibiotics. The T84 cell line was cultured in Dulbecco's modified Eagle's medium mixed 1:1 with Ham's F-12 nutrient mixture and $6 \%$ newborn calf serum containing the same concentrations of antibiotics. All cells were maintained at $37^{\circ} \mathrm{C}$ in $5 \% \mathrm{CO}_{2}$.

hCG $\beta$ Cloning, Retrovirus Production, and Establishment of Stably Expressing Cells

The above five CRC cell lines were examined for endogenous hCG expression. The Caco- 2 and WiDr cell lines highly expressed hCG, and hCG mRNA from these two cell lines was used to generate cDNA for transfection into the three low hCG-expressing cell lines LoVo, HCA7, and T84. Total RNA was isolated using TRIzol (Invitrogen, Carlsbad, CA). Reverse transcription with random hexamer primers was performed with an Ominscript RT kit (Qiagen, Valencia, CA). The sequences of the primers used for the amplification of hCG $\beta$ 498-bp cDNA were as follows: forward, 5'-GGATCCATTACCATGGAGATGTTCCAGGGG- ${ }^{\prime}$; and reverse, 5'-GAATTCTTATTGTGGGAGGATCGGGGTGTC-3' . Amplified hCG $\beta$ cDNA was digested with BamHI and EcoRI and ligated into the pCX4-puromycin retrovirus production plasmid, as previously described. ${ }^{12}$ The complete sequences of pCX4-puromycin are available from the GenBank database (https://www.ncbi.nlm.nih.gov/nuccorel AB086386; accession number AB086386). Positive clones were selected using restriction digestion and verified by DNA sequencing. Retroviruses were obtained by using 293T cells as packaging cells, transfected into LoVo, HCA7, and T84 cells, and selected with puromycin $(2 \mu \mathrm{g} / \mathrm{mL})$.

Similarly, to generate stable control LoVo, HCA7, and T84 cells with permanent expression of exogenous green fluorescent protein (GFP), the cells were transduced with a GFP-expression construct by using $\mathrm{pCX} 4$ retrovirus vectors $^{12}$ and selected by puromycin $(2 \mu \mathrm{g} / \mathrm{mL})$.

\section{Immunofluorescence Analysis and Live-Cell Imaging}

Cells were fixed in 3\% paraformaldehyde for 15 minutes at room temperature, permeabilized with $0.1 \%$ Triton X-100 in 
phosphate-buffered saline (PBS) for 4 minutes at the same temperature, and then incubated with $1 \%$ bovine serum albumin. The cells were incubated with the hCG $\beta$ antibody (1:100; sc-67357; Santa Cruz Biotechnology, Dallas, TX) at $4{ }^{\circ} \mathrm{C}$ overnight, and afterward incubated with Alexa Fluor 488-conjugated secondary antibody (1:200; Molecular Probes, Invitrogen, Waltham, MA) for 1 hour at room temperature in the dark. F-actin was visualized by phalloidin conjugated with Alexa Fluor 594 (1:50; Molecular Probes). Images were acquired using an FV-1000 confocal microscope (Olympus, Tokyo, Japan).

\section{Cell Proliferation Assay}

LoVo-GFP, LoVo-hCG $\beta$, HCA7-GFP, and HCA7-hCG $\beta$ cells were seeded in 60 -mm dishes at a density of $2 \times 10^{5}$ cells $/ \mathrm{mL}$. At days $0,2,4$, and 5 after seeding, cells were trypsinized. Cells, excluding trypan blue-stained ones, were counted using a hemocytometer, and they were expressed as means $\pm \mathrm{SD}$ of three independent measurements.

\section{Invasion Assay}

Invasion analysis was performed as described previously. ${ }^{13}$ Cells were seeded on Matrigel-coated Transwell chambers. After 24 hours, the invading cells were counted. A cell was considered invasive if its nucleus was clearly visible under a fluorescence microscope (KEYENCE BZ-9000; Keyence, Itasca, IL). The cells in full visual field $(\times 200)$ per filter were counted, and the results were expressed as means $\pm \mathrm{SD}$ of three independent measurements.

\section{Wound Healing Assay}

The wound healing assay was performed as described previously. ${ }^{14}$ Briefly, confluent cells were wounded by scraping with a P200 pipette tip. Cell movement was then observed by phase-contrast microscopy, using a $10 \times$ objective lens. Extent of cell movement was calculated at the indicated time points and expressed as means \pm SD of three independent measurements.

\section{Western Blot Analysis}

To detect hCG $\beta$ expression, cell lysates from LoVo-GFP, LoVo-hCG $\beta$, HCA7-GFP, and HCA7-hCG $\beta$ cells were prepared using a solution containing $2 \%$ SDS, $10 \%$ glycerol, $50 \mathrm{mmol} / \mathrm{L}$ Tris-HCl $(\mathrm{pH} 6.8)$, and $100 \mathrm{mmol} / \mathrm{L}$ dithiothreitol. Cytoplasmic protein $(20 \mu \mathrm{g})$ obtained from these cells was diluted in SDS-PAGE loading buffer, boiled for 5 minutes, and loaded onto 15\% SDS-PAGE gel. Membrane proteins were blocked in $1 \%$ skimmed milk in PBS with $0.1 \%$ Tween-20 for 1 hour at room temperature. The membranes were then incubated with hCG $\beta$ antibody (1:100; sc-67357; Santa Cruz Biotechnology) at room temperature for 1 hour, which was followed by the incubation at $4{ }^{\circ} \mathrm{C}$ overnight in PBS with $0.1 \%$ Tween-20 with $1 \%$ skimmed milk. Anti-rabbit polyclonal anti-p16 antibody (1:5000; H156; Santa Cruz Biotechnology) was used as the secondary antibody, and the samples were incubated in $1 \%$ skimmed milk in PBS with $0.1 \%$ Tween- 20 at room temperature for 1 hour. An enhanced chemiluminescence detection system (GE Healthcare, Buckinghamshire, UK) was used to visualize membrane hCG $\beta$.

To analyze the expression of EMT-related proteins, the primary antibodies used were anti-phosphorylated SMAD2, anti-SNAIL, anti-SLUG, anti- $\beta$-catenin, and anti-E-cadherin antibodies from the EMT Antibody Sampler Kit (1:1000; number 9782; Cell Signaling Technology, Danvers, MA) and anti-TWIST antibody (1:1000; ab50581; Abcam, Cambridge, MA). Bound antibodies were detected with peroxidase-labeled goat antibody to mouse $\mathrm{IgG}$ or goat antibody against rabbit IgG. The procedure was otherwise identical to that described above.

\section{RNA Extraction and qPCR}

Total RNA was isolated as described previously. ${ }^{15,16}$ Total RNA was isolated using the RNeasy MiniKit (Qiagen), and $1 \mu \mathrm{g}$ of RNA was converted into SLUG, SNAIL, or TWIST cDNA by reverse transcription using Superscript VILO (Invitrogen, Carlsbad, CA). The resulting cDNA was used for real-time quantitative PCR (qPCR) using SYBR Green DNA polymerase (Applied Biosystems, Warrington, UK). The sequences of primers used are provided in Table 1.

\section{PCR Array Analysis}

The expression profile of 84 EMT-related genes was determined using a 96-well human Epithelial to Mesenchymal Transition $\mathrm{RT}^{2}$ Profiler PCR Array (SABiosciences, Valencia, CA), according to the manufacturer's instructions. PCR was performed on the ABI 7900HT qPCR instrument equipped with SDS 2.3 software (Applied Biosystems), using $\mathrm{RT}^{2}$ SYBR Green/ROX qPCR Master Mix (Applied Biosystems). Data were analyzed using the $2^{-\mathrm{d} \Delta \Delta \mathrm{Ct}}$ method, according to manufacturer's instructions (Qiagen). Genes showing more than twofold change were considered biologically significant.

Table 1 Primers for Real-Time Quantitative PCR

\begin{tabular}{|c|c|c|}
\hline Gene name & Primer type & Sequence \\
\hline \multirow[t]{2}{*}{ GAPDH } & $\mathrm{F}$ & $5^{\prime}$-AGCCACATCGCTCAGACAC-3' \\
\hline & $\mathrm{R}$ & $5^{\prime}$-GCCCAATACGACCAAATCC-3' \\
\hline \multirow[t]{2}{*}{ SLUG } & $\mathrm{F}$ & 5'-TGGTTGCTTCAAGGACACAT-3' \\
\hline & $\mathrm{R}$ & 5'-GTTGCAGTGAGGGCAAGAA-3' \\
\hline \multirow[t]{2}{*}{ SNAIL } & $\mathrm{F}$ & $5^{\prime}$-GCTGCAGGACTCAATCCAGA-3' \\
\hline & $\mathrm{R}$ & 5'-ATCTCCGGAGGTGGGATG-3' \\
\hline \multirow[t]{2}{*}{ TWIST } & $\mathrm{F}$ & 5'-GGCATCACTATGGACTTTCTCTATT-3' \\
\hline & $\mathrm{R}$ & $5^{\prime}$-GGCCAGTTTGATCCCAGTATT- $3^{\prime}$ \\
\hline
\end{tabular}

$F$, forward; $R$, reverse. 
Assessment of hCG $\beta$-Induced TGF- $\beta$ Receptor Activation

Untransfected HCA7 cells were treated for 24 hours with $100 \mathrm{mIU} / \mathrm{mL}$ recombinant hCG $\beta$ (GenWay Biotech, San Diego, CA) or $5 \mathrm{ng} / \mathrm{mL}$ recombinant TGF- $\beta$ (SigmaAldrich, St. Louis, MO), in combination with $10 \mu \mathrm{mol} / \mathrm{L}$ TGF- $\beta$ receptor 1 inhibitor (SB431542) or $20 \mu \mathrm{g} / \mathrm{mL}$ TGF- $\beta$ receptor 2 inhibitor (anti-TGFBR2 antibody; Abcam). There were seven separate groups: HCA7 alone, HCA7 + hCG $\beta$, HCA7 + hCG $\beta$ + SB431542, HCA7 + hCG $\beta$ + antiTGFBR2 antibody, HCA7 + TGF- $\beta$, HCA7 + TGF$\beta+$ SB431542, and HCA7 + TGF- $\beta+$ anti-TGFBR2 antibody.

After treatment, total RNA was isolated using the RNeasy MiniKit, and RNA was converted into SLUG, SNAIL, or TWIST cDNA by reverse transcription. The resulting cDNA was used for qPCR using SYBR Green DNA polymerase (Applied Biosystems).

\section{Murine Xenograft Model}

BALB/c female nude mice (Charles River, Yokohama, Japan) were maintained according to the guidelines of the Institutional Animal Care and Use Committee of Hokkaido University Graduate School of Medicine (Sapporo, Japan). Tumors were generated by s.c. injections of $5 \times 10^{6}$ LoVoGFP or LoVo-hCG $\beta$ cells. Tumor dimensions were measured once per week, and tumor volume was calculated using the following formula: tumor volume $\left(\mathrm{cm}^{3}\right)=$ (the smallest diameter $)^{2} \times($ the largest diameter $) / 2$.

The mice were monitored daily and sacrificed at day 30 . Tumors were removed, fixed in 10\% formalin, and processed according to routine histologic protocols. Standard hematoxylin and eosin sections were obtained, and tumor microvessel density was quantified (number of vessels/high-power field).

A peritoneal metastasis model was established as described previously. ${ }^{17}$ Briefly, $1 \times 10^{6}$ LoVo-GFP or LoVo-hCG $\beta$ cells were injected into the peritoneal cavity. The animals were monitored daily and sacrificed at day 30 . The incision was performed to allow the peritoneal cavity to be imaged, and the extent of peritoneal metastatic disease was determined using a modified peritoneal cancer index (mPCI). ${ }^{18}$ mPCI allowed for assessment of the distribution of tumor in the abdomen and pelvis and was calculated by combining the size scores (range, 1 to 3 ) of the lesions observed in the abdominopelvic regions. This index was adapted to the tumor size in mice with the following lesion size scores: tumors $<2.0 \mathrm{~mm}$, score of 1 ; tumors from 2.1 to $5.0 \mathrm{~mm}$, score of 2 ; and tumors $>5.0 \mathrm{~mm}$ or confluent tumors, score of 3 , as previously described. ${ }^{17}$

\section{Statistical Analysis}

The $\chi^{2}$ test or the Fisher exact test were used to examine correlations between hCG $\beta$ expression and clinicopathological data. Survival curves for patients were generated using the Kaplan-Meier method. A two-tailed $t$-test was used to compare differences between two groups. The results were expressed as the means \pm SD. Significance level was set at $P<0.05$. Ekuseru-Toukei 2012 software for Windows was used for analysis (Social Survey Research Information Co., Ltd., Tokyo, Japan).

\section{Results}

hCG $\beta$ Expression in CRC Tissue Samples Correlates with Clinicopathological Features and Poor Patient Outcome

In the beginning, hCG $\beta$ expression in CRC tissue samples was evaluated, and those samples with the cytoplasmic staining of more than five epithelial clusters of cells (magnification, $\times 400$ ) were considered to be hCG $\beta$ positive. Of 80 CRC samples, 13 (16.3\%) were hCG $\beta$ positive on IHC (Figure 1A). Clinicopathological data are summarized in Table 2. Histologic hCG $\beta$ positivity significantly correlated with histologic grade $(P=0.031)$, lymph node metastasis $(P=0.021)$, and lymphatic invasion $(P=0.011)$. Furthermore, hCG $\beta$-positive patients had significantly poorer outcomes than hCG $\beta$-negative patients $(P<0.05)$ (Figure $1 \mathrm{C})$.

\section{Correlations between Histologic Expression of hCG $\beta$ and Serum hCG $\beta$}

To explore the clinical significance of hCG $\beta$ secretion in serum, hCG $\beta$ levels were measured in 54 preoperative serum samples. Serum samples from 13 of the 54 patients ( $24.1 \%$ ) were positive for hCG $\beta$ ( $\geq 2 \mathrm{pmol} / \mathrm{L}$ ). Serum hCG $\beta$ positivity significantly correlated with lymph node metastasis $(P=0.022)$ and pathologic stage $(P=0.022)$; however, there was no correlation with overall survival (Figure 1D). Median serum levels measured in serologically hCG $\beta$-negative and hCG $\beta$-positive patients were 0.57 and $3.46 \mathrm{pmol} / \mathrm{L}$, respectively $(P<0.001)$.

Thirty-four patients showed concordance in the histologic and serologic results (4 histologic positive/serologic positive and 30 histologic negative/serologic negative), and 20 patients showed discordant results (11 histologic positive/ serologic negative and 9 histologic negative/serologic positive). In patients who were histologically and serologically positive for hCG $\beta$, multifocal tumor budding with hCG $\beta$ expression was observed (Figure 1B), suggesting that hCG $\beta$ expression may be associated with tumor invasion. Notably, patients who were histologically and serologically positive for hCG $\beta$ had an unfavorable prognosis compared with all other expression subgroups (Figure 1E).

Overexpression of hCG $\beta$ Promotes Tumor Cell Invasion and Migration but Not Proliferation

To explore the biological role of hCG $\beta$ in CRC, five types of CRC cell lines (LoVo, WiDr, T84, HCA7, and Caco-2) 
A

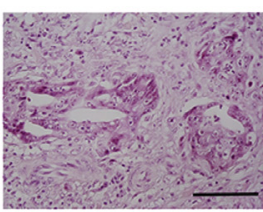

$H \& E$

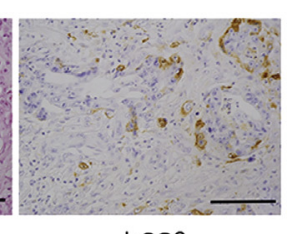

hCG $\beta$
B

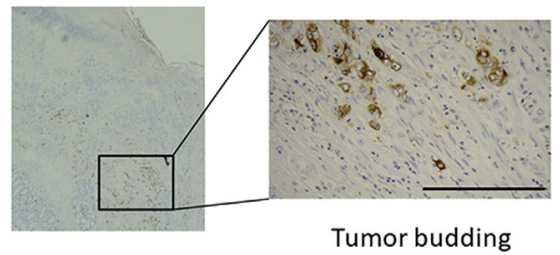

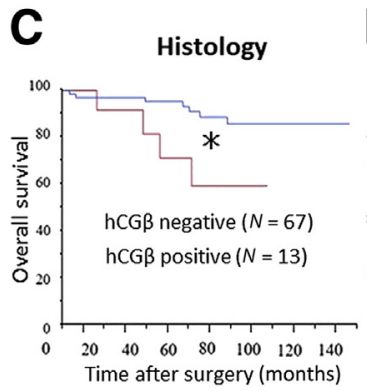
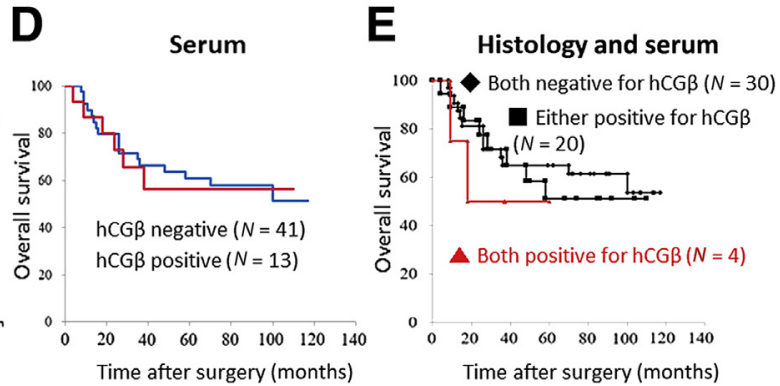

Figure 1 Free $\beta$ human chorionic gonadotropin (hCG $\beta$ ) expression in human colorectal cancer samples and correlations with prognosis. A: Examples of hematoxylin and eosin (H\&E) and hCG $\beta$ immunohistochemistry. B: Tumor budding with hCG $\beta$ expression, seen in a case histologically and serologically positive for hCG $\beta$. C: Histologically hCG $\beta$-positive patients have significantly poorer survival compared with hCG $\beta$-negative patients. D: Survival of serologically hCG $\beta$-positive patients does not differ significantly from that of hCG $\beta$-negative patients. E: The patients who are both histologically and serologically positive for hCG $\beta$ have poorer survival compared with the other expression subgroups, but the differences are not statistically significant. ${ }^{*} P<0.05$ negative versus positive (Kaplan-Meier survival analysis). Scale bars $=50 \mu \mathrm{m}(\mathbf{A}$ and $\mathbf{B})$. were used and the endogenous expression of hCG $\beta$ was examined by Western blotting. Pretransfection, hCG $\beta$ was strongly expressed in Caco-2 and $\mathrm{WiDr}$ cell lines compared with LoVo, HCA7, and T84 cell lines (Figure 2A). hCG heterodimeric complex was identified in both types of cells (Caco-2 and WiDr) as well. A retroviral infection system was used to overexpress hCG $\beta$ in three types of CRC cells (LoVo, HCA7, and T84 cells) that do not show the endogenous expression of hCG $\beta$. After transfection, all five cell lines showed similar hCG $\beta$ expression (Figure 2B).

Ectopic production of hCG $\beta$ contributes to the increase in cell metastatic potential in an autocrine manner, so we examined the concentration of hCG $\beta$ in the culture medium of hCG $\beta$-overexpressing cells (LoVo-hCG $\beta$ and HCA7hCG $\beta$ ). We confirmed that these cells release hCG $\beta$ in the culture medium, allowing them to be continually exposed to the locally produced hCG $\beta$ (Figure 2C).

Table 2 Correlations between hCG $\beta$ Expression and Patient Clinicopathological Features

\begin{tabular}{|c|c|c|c|c|c|c|c|c|}
\hline \multirow[b]{2}{*}{ Parameter } & \multirow[b]{2}{*}{ Total, $N$} & \multicolumn{3}{|c|}{ Tissue hCG $\beta(N=80)$} & \multirow[b]{2}{*}{ Total, $N$} & \multicolumn{3}{|c|}{ Serum hCG $\beta(N=54)$} \\
\hline & & $\begin{array}{l}\text { Positive } \\
(N=13)\end{array}$ & $\begin{array}{l}\text { Negative } \\
(N=67)\end{array}$ & $P$ value & & $\begin{array}{l}\text { Positive } \\
(N=13)\end{array}$ & $\begin{array}{l}\text { Negative } \\
(N=41)\end{array}$ & $P$ value \\
\hline Well differentiated & 34 & 2 & 32 & 0.031 & 17 & 6 & 11 & 0.191 \\
\hline Moderately/poorly differentiated & 46 & 11 & 35 & & 37 & 7 & 30 & \\
\hline \multicolumn{9}{|l|}{ Pathologic T stage } \\
\hline \multicolumn{9}{|l|}{ Pathologic $\mathrm{N}$ stage } \\
\hline pNO & 53 & 5 & 48 & 0.021 & 35 & 5 & 30 & 0.022 \\
\hline pN1-3 & 27 & 8 & 19 & & 19 & 8 & 11 & \\
\hline \multicolumn{9}{|l|}{ Overall pathologic stage } \\
\hline I-II & 53 & 5 & 48 & 0.021 & 35 & 5 & 30 & 0.022 \\
\hline \multicolumn{9}{|l|}{ Vascular invasion } \\
\hline Absent & 32 & 4 & 28 & 0.458 & 15 & 3 & 12 & 0.664 \\
\hline Present & 48 & 9 & 39 & & 39 & 10 & 29 & \\
\hline \multicolumn{9}{|l|}{ Recurrence } \\
\hline No & 68 & 10 & 58 & 0.373 & 44 & 11 & 33 & 0.739 \\
\hline Yes & 12 & 3 & 9 & & 10 & 2 & 8 & \\
\hline
\end{tabular}

Bold indicates statistically significant difference $(P<0.05)$.

$\mathrm{hCG} \beta$, free $\beta$ human chorionic gonadotropin. 
A

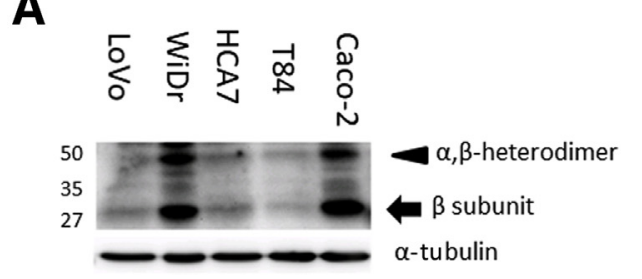

C

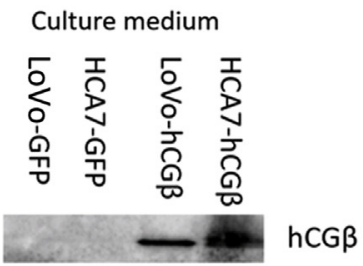

E

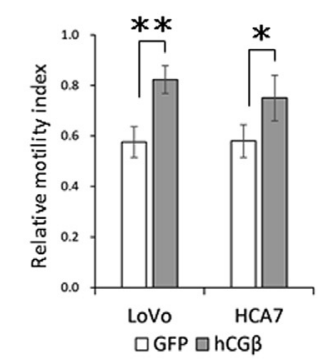

B
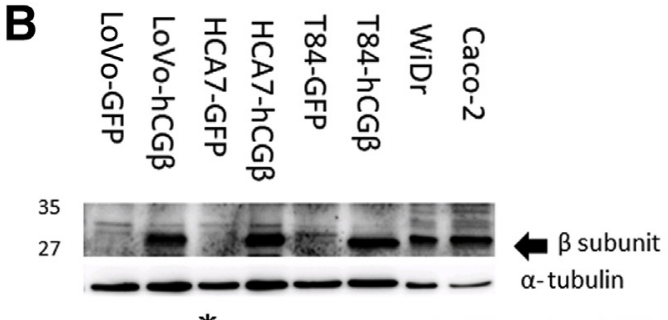

D

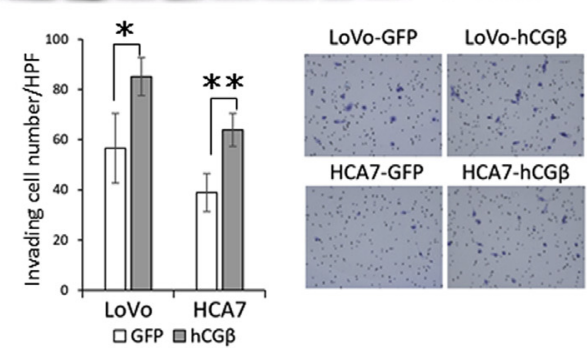

$\mathbf{F}$

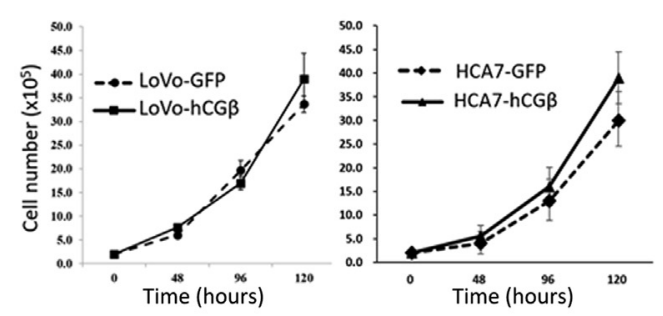

Figure 2 The effects of free $\beta$ human chorionic gonadotropin (hCG $\beta$ ) overexpression on tumor cell invasiveness and migratory potential. A: Pretransfection, hCG $\alpha \beta$ and hCG $\beta$ are overexpressed only in Caco-2 and WiDr cells (Western blot analysis). B: After transfection, hCG $\beta$ is overexpressed in LoVo, HCA7, and T84 cells (LoVo-hCG $\beta$, HCA7-hCG $\beta$, and T84-hCG $\beta$ ) compared with green fluorescent protein (GFP)-expressing controls (LoVo-GFP, HCA7-GFP, and T84-GFP). Caco-2 and WiDr cells were used as positive controls (Western blot analysis). C: hCG $\beta$ is detectable in the culture medium of hCG $\beta$-overexpressing cells (Western blot analysis). D: hCG $\beta$-overexpressing LoVo and HCA7 cells demonstrate significantly increased invasiveness compared with controls. (Representative images are shown.) E: hCG $\beta$-overexpressing LoVo and HCA7 cells demonstrate significantly increased migratory potential compared with controls. The solid lines indicate the advancing edge of cells at the beginning of the experiment ( 0 hours), whereas the dotted lines indicate the advancing edge of cells at the end of the experiment (24 hours). Representative images are shown. F: Cell proliferation does not differ significantly between hCG $\beta$ overexpressing cells and control cells. ${ }^{*} P<0.05,{ }^{*} P<0.01$. HPF, high-power field.

Furthermore, hCG $\beta$ stimulates trophoblast invasion and migration during pregnancy, and local invasion represents the characteristic clinical feature of CRC. Therefore, we evaluated in vitro cell invasion and migration using LoVohCG $\beta$ and HCA7-hCG $\beta$ cells. In the LoVo and HCA7 cell lines, we found overexpression of hCG $\beta$ led to a significant increase in cell invasiveness $(P<0.05$ and $P<0.01$, respectively) (Figure 2D) and migratory ability $(P<0.01$ and $P<0.05$, respectively) (Figure $2 \mathrm{E}$ ) compared with control cells. The T84 cell line demonstrated excessive cell cohesiveness, rendering assessment of single-cell morphology, invasion, and migration difficult; it was, therefore, not used in the remainder of the study.

We also performed a cell proliferation assay on LoVo and HCA7 cells, but no significant differences were identified between hCG $\beta$-overexpressing cells and control cells (Figure 2F).

\section{Immunofluorescence Analysis and Live-Cell Imaging of hCG $\beta$-Expressing Tumor Cells}

Actin cytoskeleton maintains the cellular architecture and mediates cell movements. To explore the association between its dynamics and hCG $\beta$ expression, we performed fluorescence microscopic analysis of hCG $\beta$-overexpressing cells. Untransfected (wild-type) LoVo cells had epithelioid morphologic features, with scant membrane ruffling and little actin organization (Figure 3, A and B). The morphology of LoVo-hCG $\beta$ cells had a spindled, mesenchymal appearance, with scattered membrane ruffles (Figure 3, C and D). These morphologic alterations are typically seen during EMT with many actively migrating cells. We examined the intracellular localization of hCG $\beta$ in HCA7-hCG $\beta$ cells and determined that the diffuse cytoplasmic hCG $\beta$ signals and some of the dot-like spots along the cellular membrane merged with actin, which was observed as orange signals in these cells (Supplemental Figure S1).

\section{hCG $\beta$ 0verexpression Promotes EMT in Tumor Cells}

As shown above, we explored that hCG $\beta$ expression promoted cell invasion and migration; however, the detailed molecular mechanism was unclear. We herein focused on the fact that hCG-overexpressing cells represented a spindle 


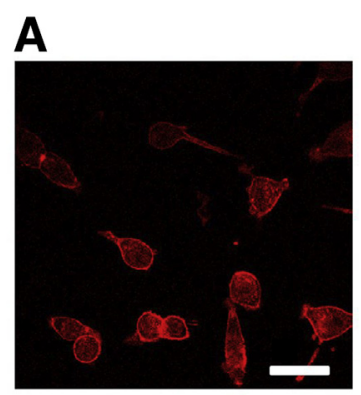

LoVo

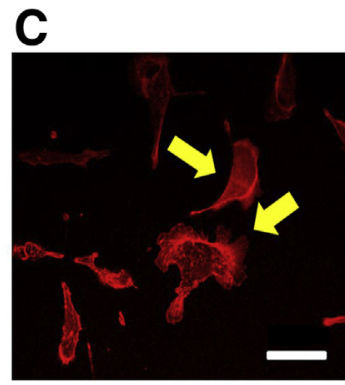

LoVo-hCG $\beta$

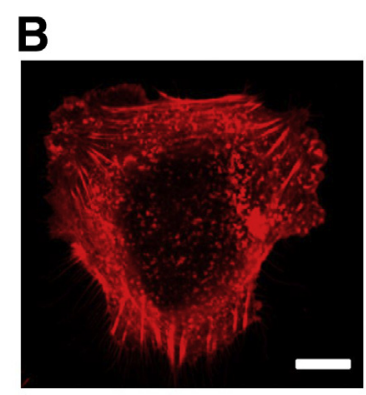

LoVo

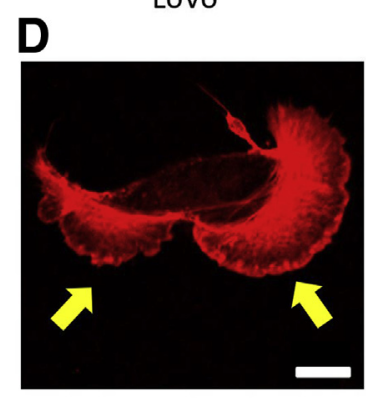

LoVo-hCG $\beta$

Figure 3 Immunofluorescence analysis and live-cell imaging of tumor cell free $\beta$ human chorionic gonadotropin (hCG $\beta$ ) expression. A and $\mathbf{B}$ : Morphology of untransfected (wild-type) LoVo cells. Cells have an epithelioid morphology with no membrane ruffling and little actin organization. C and D: Morphology of LoVo-hCG $\beta$ cells. Cells have a more pleomorphic appearance with membrane ruffling (arrows). Scale bars: $50 \mu \mathrm{m}$ (A and $\mathbf{C}$ ); $10 \mu \mathrm{m}(\mathbf{B}$ and $\mathbf{D})$

shape cellular morphology, one of the typical phenotypes during EMT. The EMT process can also be evaluated by the altered expression of epithelial and mesenchymal markers, and we examined the expression of EMT marker genes, including E-cadherin, SNAIL, SLUG, and TWIST, in

hCG $\beta$-overexpressing cells and control cells. On Western blot analysis, SNAIL, SLUG, TWIST, and phosphorylated SMAD2 were upregulated and E-cadherin was downregulated in HCA7-hCG $\beta$ cells compared with control cells (Figure 4A). SMAD phosphorylation, which can be caused by TGF- $\beta$ receptor stimulation during EMT, was also upregulated in both LoVo-hCG $\beta$ cells and HCA7-hCG $\beta$ cells compared with the control cells. We subsequently performed qPCR to analyze the expression levels of SLUG, SNAIL, and TWIST. The mRNA levels of SNAIL and TWIST were significantly upregulated in HCAhCG $\beta$ cells compared with control cells $(P<0.05$ and $P<0.001$, respectively) (Figure 4B).

Because LoVo cells did not demonstrate significant protein expression differences in SNAIL and SLUG on Western blot analysis (Figure 4A), we further examined this cell line using the EMT PCR array. The mRNA levels of 11 genes were altered more than twofold in LoVo-hCG $\beta$ cells compared with control cells, in which fibronectin 1 , TWIST1, and SNAIL2 were upregulated by 4.38-, 3.60-, and 2.11-fold, respectively (Figure 4C and Table 3).

\section{hCG $\beta$ Induces EMT through TGF- $\beta$ Receptor Activation}

To confirm the hCG $\beta$-induced TGF- $\beta$ receptor activation during EMT, we analyzed hCG $\beta$-induced expression of EMT-associated genes, such as SLUG (official name, SNAI2), SNAIL, and TWIST, in the presence of SB431542 and anti-TGFBR2 antibody. In untransfected HCA7 cells, the addition of hCG $\beta$ or TGF- $\beta$ significantly increased SNAIL and TWIST expression $(P<0.01)$ (Figure 5). Furthermore, we observed that cotreatment with SB431542 or anti-TGFBR2 antibody abolished this response $(P<0.05)$ (Figure 5). These results suggest the novel
A

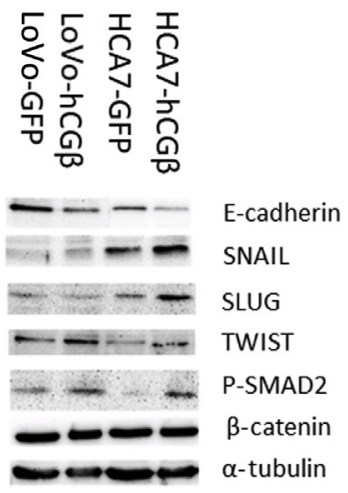

B

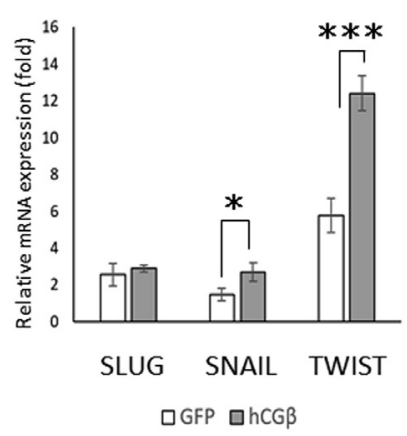

HCA7-GFP versus HCA7-hCG $\beta$
C

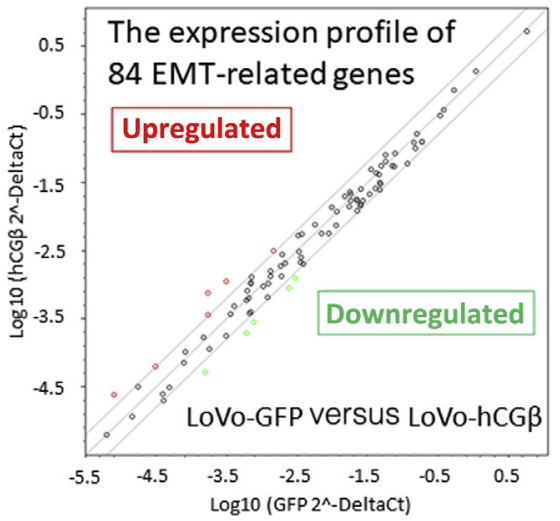

Figure 4 Expression of epithelial-to-mesenchymal transition (EMT) proteins in free $\beta$ human chorionic gonadotropin (hCG $\beta$ ) -overexpressing cells. A: HCA7-hCG $\beta$ cells show decreased E-cadherin and increased SNAIL, SLUG, TWIST, and phosphorylated SMAD2 expression compared with control cells (Western blot analysis). B: Expression levels of mRNAs of EMT makers (SLUG, SNAIL, and TWIST) were examined by real-time RT-PCR in HCA7 cells overexpressing hCG $\beta$ or green fluorescent protein (GFP). HCA7-hCG $\beta$ cells also show increased SNAIL and TWIST mRNA expression compared with control cells. C: EMT RT ${ }^{2}$ profiler PCR array results for LoVo cells. Six genes are upregulated (red circles), and five genes are downregulated (green circles), in LoVo-hCG $\beta$ cells compared with control cells. Only genes with greater than twofold change are indicated. Gene names, gene symbols, and observed fold changes are indicated in Table 3 . ${ }^{\star} P<0.05$, $* * * P<0.001$. 
Table 3 Epithelial-to-Mesenchymal Transition RT ${ }^{2}$ Profiler PCR Array Results (LoVo-hCG $\beta$ versus LoVo-GFP)

\begin{tabular}{lllll}
\hline Position & Gene symbol & Gene name & Fold difference & GenBank accession no. \\
\hline A04 & BMP2 & Bone morphogenetic protein 2 & 2.14 & NM_001200 \\
A12 & COL3A1 & Collagen, type III, $\alpha$ 1 & 3.03 & NM_000090 \\
B10 & FN1 & Fibronectin 1 & 4.38 & NM_002026 \\
D12 & PDGFRB & Platelet-derived growth factor receptor, $\beta$ polypeptide & 2.02 & NM_002609 \\
E11 & SNAIL2 & Snail homolog 2 & 2.11 & NM_003068 \\
G04 & TWIST1 & Twist homolog 1 & 3.60 & NM_000474 \\
C02 & GSC & Goosecoid homeobox & -3.10 & NM_173849 \\
C05 & IL1RN & IL-1 receptor antagonist & -2.42 & NM_000577 \\
D01 & KRT7 & Keratin 7 & -2.67 & NM_005556 \\
D03 & MMP2 & Matrix metallopeptidase 2 & -3.00 & NM_004530 \\
D05 & MMP9 & Matrix metallopeptidase 9 & -2.72 & NM_004994 \\
\hline
\end{tabular}

GenBank: https://www.ncbi.nlm.nih.gov/genbank.

GFP, green fluorescent protein; hCG $\beta$, free $\beta$ human chorionic gonadotropin.

collaboration between hCG $\beta$ and TGF- $\beta$ to induce EMT in human colorectal cancer cells.

\section{hCG $\beta$ Expression Accelerates Tumor Formation in Mice}

To investigate the in vivo evidence of hCG $\beta$ expression during tumor progression, we subcutaneously and intraperitoneally introduced hCG $\beta$-overexpressing cells into the mice. hCG $\beta$-overexpressing tumors had slightly higher tumor volume compared with control tumors, although the difference was not statistically significant (Figure 6A). However, pathologic examination revealed hCG $\beta$-overexpressing tumors were more poorly differentiated, with reduced glandular formation and increased cellular pleomorphism, compared with control tumors (Figure 6B). Moreover, we analyzed tumor angiogenesis in these tumors, because angiogenesis is crucial not only for tumor growth but for the invasiveness and metastatic potential of tumor cells. The immunohistochemical evaluation of angiogenesis using an antibody against CD31, a well-established endothelial cell marker, revealed that hCG $\beta$-overexpressing tumors harbored significantly more tumor microvessels compared with control tumors $(P<0.01)$ (Figure $6 \mathrm{C})$. On the other hand, Mib-1 expression between hCG $\beta$-overexpressing mouse xenograft tumors and GFP control tumors is similar; however, we found that membrane expression of E-cadherin was significantly decreased in hCG $\beta$-overexpressing mouse xenograft tumors compared with GFP control tumors (Supplemental Figure S2). These results were compatible with the phenotype of EMT as a result of TGF- $\beta$ stimulation by hCG $\beta$.

We next examined the effects of hCG $\beta$ overexpression for metastasis using an i.p. metastatic mouse model and mPCI assessment, because distant metastases, including i.p. dissemination, lead to clinically unfavorable prognosis.

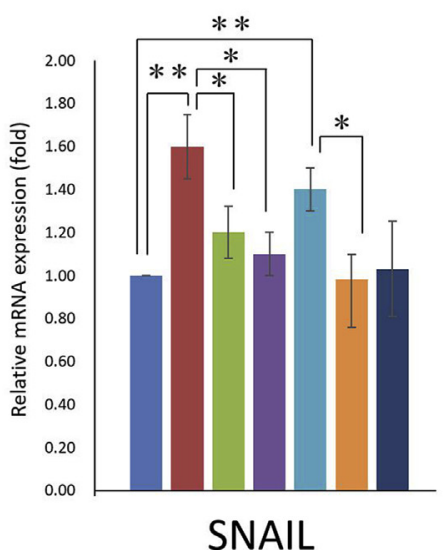

— HCA7

- HCA7+hCG $\beta$

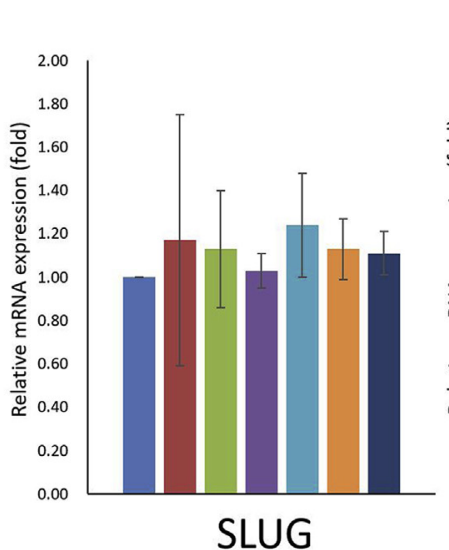

HCA7+TGF- $\beta$

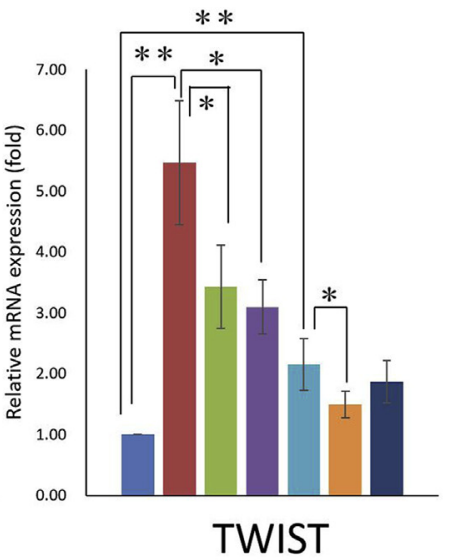

口 HCA7+TGF- $\beta+$ anti-TGFBR2

Figure 5 Effects of transforming growth factor (TGF)- $\beta$ receptor inhibitors on free $\beta$ human chorionic gonadotropin (hCG $\beta$ )-induced epithelial-tomesenchymal transition protein expression. Untransfected HCA7 cells were treated with either hCG $\beta$ or TGF- $\beta 1$, in combination with either TGF- $\beta$ receptor 1 inhibitor (SB431542) or TGF- $\beta$ receptor 2 inhibitor (anti-TGFBR2 antibody). SNAIL and TWIST mRNA increases with hCG $\beta /$ TGF- $\beta 1$, which can be reversed by SB431542/anti-TGFBR2 antibody. SLUG mRNA does not demonstrate a similar response. Values are means \pm SD from three independent experiments. ${ }^{*} P<0.05,{ }^{* *} P<0.01$ 
A
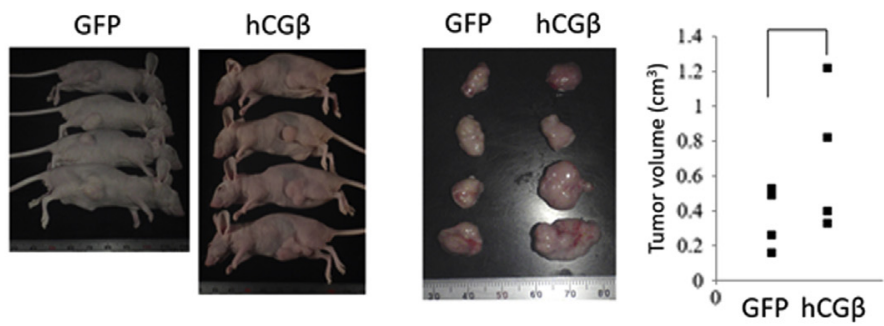

B
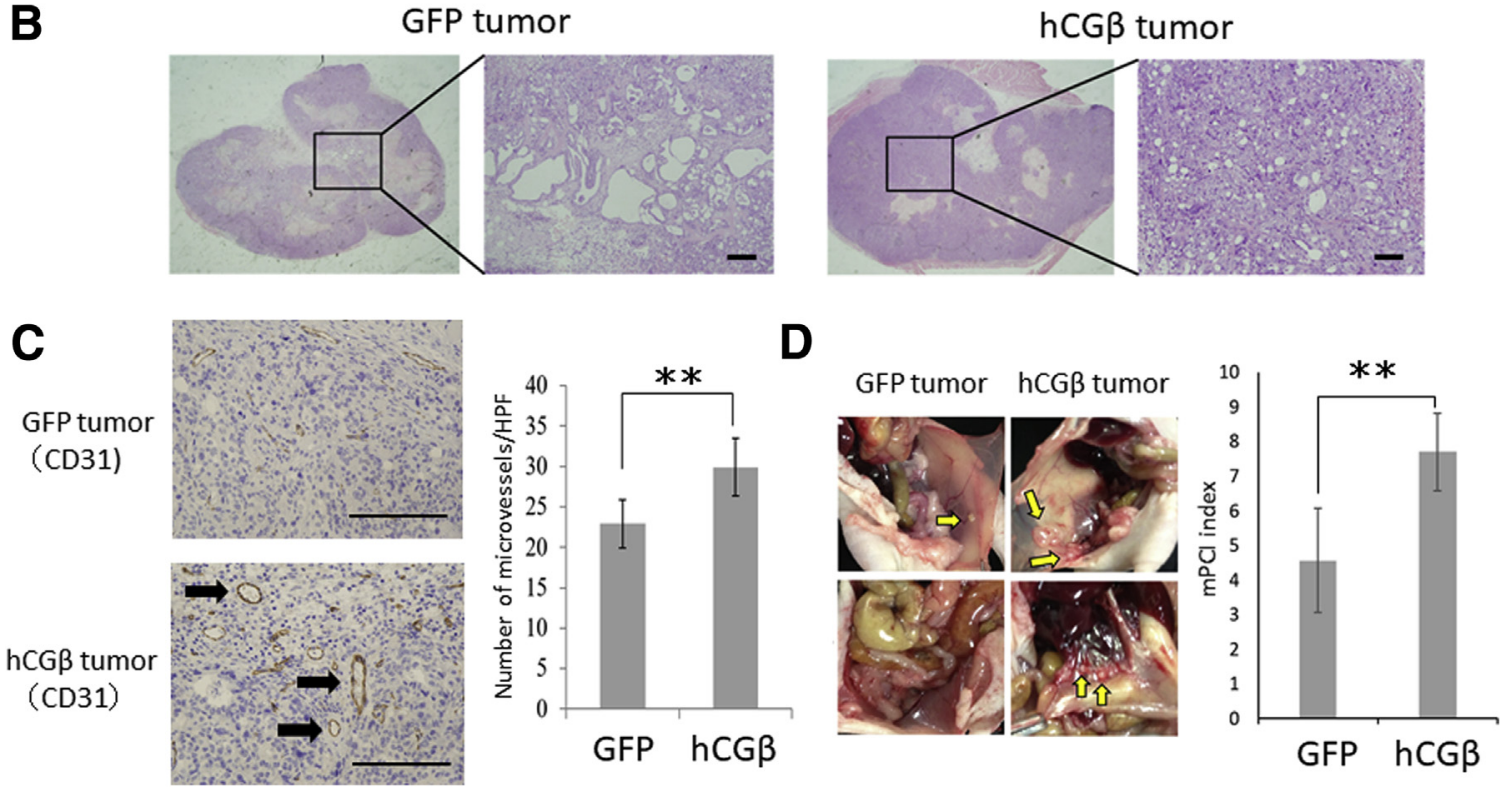

Figure 6 Effects of free $\beta$ human chorionic gonadotropin (hCG $\beta$ ) overexpression on tumor growth in the murine model. A: hCG $\beta$-overexpressing tumors show slight increase in tumor volume compared with control tumors, although the difference is not statistically significant. B: hCG $\beta$-overexpressing tumors are more poorly differentiated compared with control tumors. C: hCG $\beta$-overexpressing tumors contain significantly more microvessels (arrows) compared with control tumors. CD31 is an immunohistochemical marker that highlights endothelial cells. D: At 30 days after i.p. injection, the modified peritoneal cancer index (mPCI) is significantly higher in mice inoculated with LoVo-hCG $\beta$ cells compared with mice inoculated with control cells. Arrows indicate peritoneal metastases. ${ }^{* *} P<0.01$. Scale bars $=100 \mu \mathrm{m}$ (B and $\left.\mathbf{C}\right)$. GFP, green fluorescent protein; HPF, high-power field.

At 30 days after i.p. injection, the mPCI was significantly increased in mice inoculated with LoVo-hCG $\beta$ cells compared with mice inoculated with control cells, suggesting that hCG $\beta$ promotes tumor growth once metastasis has occurred $(P<0.01)$ (Figure $6 \mathrm{D}$ and Supplemental Figure S3). Table 4 shows the metastatic sites in all mice. Notably, one mouse in the LoVo-hCG $\beta$ group developed metastases outside the peritoneum (lung).

\section{Discussion}

In this study, we have shown hCG $\beta$ expression in CRC is associated with adverse patient outcomes. Furthermore, hCG $\beta$-overexpressing CRC cell lines display an important role in the development of metastatic behavior of CRC cells by mediating the EMT, which is crucial for cancer growth, invasion, and malignancy.

On the basis of these results, we propose that hCG $\beta$ may be a novel prognostic biomarker of the invasive CRC, especially as a marker of disease recurrence in patients with curative resection. The histologic and IHC findings were similar to what had been reported in the literature. The positivity rate of $16.3 \%$ was at the lower end of those reported previously (17\% to $52 \%),{ }^{5,19-21}$ which may be attributable to differing criteria for IHC positivity. We showed a correlation with histologic grade, lymph node metastasis, and lymphatic invasion. The association of hCG $\beta$ positivity with lymph node metastasis is of particular interest, because if hCG $\beta$ is detected in an endoscopically resected specimen, it may indicate a latent risk for lymph node metastasis, even though the current standard protocol for low-risk CRC patients (ie, those with minimal submucosal invasion and no lymphatic invasion) does not recommend additional therapy if endoscopic resection is complete. The aggressiveness of hCG $\beta$-overexpressing tumors was also seen in the murine model, where they were larger, contained more microvessels, and had a higher mPCI.

Serum hCG $\beta$ level has been shown to be associated with unfavorable prognosis in past studies. ${ }^{11,22}$ However, in our study, serum hCG $\beta$ did not correlate with overall survival, and $37.0 \%$ (20/54) of patients showed discordance between tissue IHC and serum levels. These results may be attributable to heterogeneity of hCG $\beta$ expression in histologic 
Table 4 Metastatic Sites and Modified Peritoneal Cancer Index Scores after i.p. Injection

\begin{tabular}{|c|c|c|c|c|c|c|c|c|c|c|}
\hline \multirow[b]{2}{*}{ Mouse no. } & \multirow[b]{2}{*}{ Cell line } & \multicolumn{4}{|l|}{ Metastasis site } & \multicolumn{5}{|c|}{ Modified peritoneal cancer index score } \\
\hline & & M1 & M2 & M3 & M4 & M1 & M2 & M3 & M4 & Total score \\
\hline 1 & LoVo-GFP & Peritoneum & Mesentery & & & 2 & 1 & None & None & 3 \\
\hline 3 & LoVo-GFP & Mesentery & Peritoneum & Liver & & 3 & 2 & 1 & None & 6 \\
\hline 4 & LoVo-GFP & Peritoneum & Mesentery & Diaphragm & & 2 & 2 & 2 & None & 6 \\
\hline 5 & LoVo-GFP & Mesentery & Peritoneum & & & 3 & 2 & None & None & 5 \\
\hline 8 & LoVo-hCG $\beta$ & Pelvic cavity & Peritoneum & Mesentery & & 3 & 3 & 2 & None & 8 \\
\hline 9 & LoVo-hCG $\beta$ & Peritoneum & Mesentery & Greater omentum & Lesser omentum & 2 & 2 & 2 & 1 & 7 \\
\hline 10 & LoVo-hCG $\beta$ & Pelvic cavity & Peritoneum & Mesentery & Lung & 3 & 3 & 2 & 1 & 9 \\
\hline 11 & LoVo-hCG $\beta$ & Mesentery & Pelvic cavity & Peritoneum & Retroperitoneum & 3 & 2 & 2 & 2 & 9 \\
\hline 12 & LoVo-hCG $\beta$ & Peritoneum & Mesentery & Pelvic cavity & & 3 & 2 & 3 & None & 8 \\
\hline
\end{tabular}

GFP, green fluorescent protein; hCG $\beta$, free $\beta$ human chorionic gonadotropin.

sections, variability in pathologic interpretation of IHC positivity, or type of serum assay used. Similar to prior studies, ${ }^{5,23}$ there was a trend that patients who were both histologically and serologically positive for hCG $\beta$ had an unfavorable prognosis, although the result was not statistically significant. If this trend is confirmed with larger patient cohorts, hCG $\beta$ may be used as a novel prognostic biomarker in invasive $\mathrm{CRC}$, especially as a marker of disease recurrence after curative resection.

Our results suggest hCG $\beta$ is a potential therapeutic target in the treatment of invasive CRC. A phase 2 clinical trial in patients with colorectal cancer was completed in 2002. In a clinical trial, hCG $\beta$ vaccine was shown to considerably extend the survival of advanced CRC patients, in whom anti-hCG antibody production after hCG $\beta$ vaccination was associated with longer overall survival (45 weeks' median survival; $P=0.002) .{ }^{24}$ However, this vaccine is expected to be of benefit only in patients with circulating hCG $\beta$. Phase 3 trials have not been initiated yet; the targeting of hCG $\beta$, whether by vaccines or recombinant antibodies, may be a novel therapeutic option for advanced CRC with aberrant hCG $\beta$ expression.

To the best of our knowledge, this is the first study to suggest a putative mechanism underlying the hCG $\beta$-EMT pathway and demonstrate the significance of TGF- $\beta$ signaling in CRC. Using two independent cell lines, with stable overexpression of $\mathrm{hCG} \beta$, we showed that hCG $\beta$ overexpressing CRC cell lines acquired a spindled mesenchymal appearance, demonstrated increased malignant potential compared with their control counterparts, and showed altered expression of EMT-related proteins, including E-cadherin, SNAIL, TWIST, and phosphorylated
A

\section{Autocrine effect}

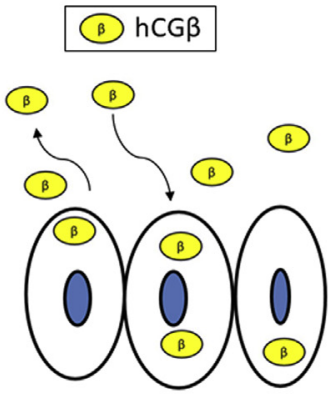

hCG $\beta$ overexpression cells

C Mesenchymal phenotype

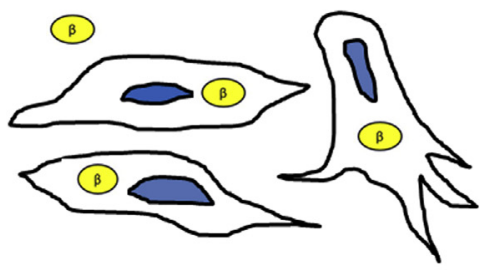

B hCG $\beta$ binds to the TGF $\beta$ receptor
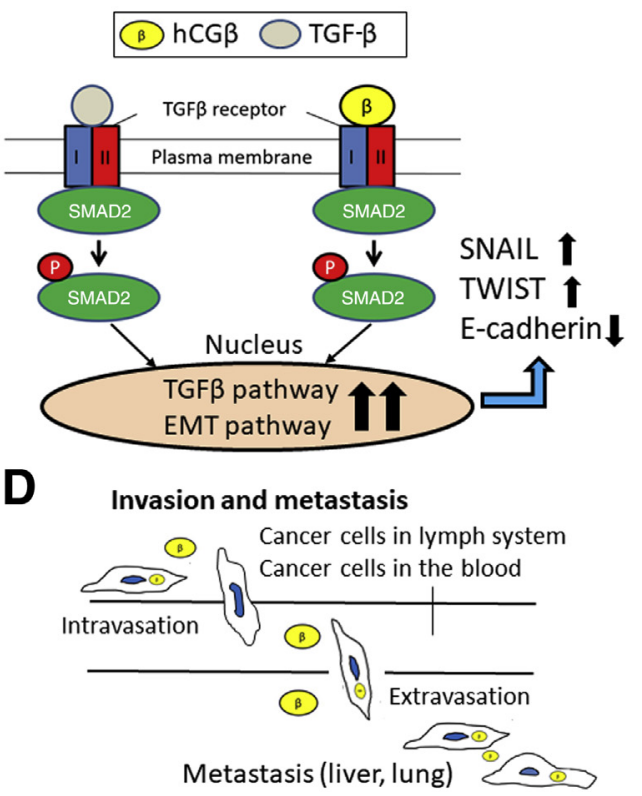

Figure 7 Proposed model of free $\beta$ human chorionic gonadotropin (hCG $\beta$ )-induced epithelial-to-mesenchymal transition (EMT) in colorectal cancer. A: Cancer cells secrete hCG $\beta$, which acts in an autocrine manner. B: hCG $\beta$ binds to the transforming growth factor (TGF)- $\beta$ receptor, activating downstream cascades and leading to altered transcription of EMT-related proteins (eg, SNAIL, TWIST, and E-cadherin). C: The proteins induce a morphologic change in the cancer cells, which acquire a mesenchymal phenotype. D: The increased malignant potential of these cells allows for invasion and metastasis. 
SMAD2. These changes resulted from activation of the TGF- $\beta$ signaling pathway, because they were effectively reversed by TGF- $\beta$ receptor inhibitors.

Additional evidence exists for hCG $\beta$ signaling through the TGF- $\beta$ pathway. ${ }^{25}$ High levels of TGF- $\beta$ and its receptor are commonly found in CRC ${ }^{26,27}$ hCG $\beta$ shows significant morphologic similarity with TGF- $\beta$, because a four-peptide cysteine knot structure is present in both proteins ${ }^{9,28}$ and the $T G F B$ gene is located in close proximity to the hCG $\beta$ gene on chromosome $19 .^{29}$ Furthermore, hCG $\beta$ has two different receptor binding sites, for the hCG/LH receptor and the TGF- $\beta$ receptor.

We, therefore, propose the following mechanism for EMT in CRC with hCG $\beta$ overexpression, summarized in Figure 7. Tumor cells secrete hCG $\beta$, which act via an autocrine manner through TGF- $\beta$ receptors. This leads to downstream events, including SMAD2 phosphorylation, and altered transcription of EMT-related proteins, such as SNAIL, TWIST, and E-cadherin. The tumor cells then acquire a mesenchymal phenotype, which is capable of invasion and metastasis.

Although we have shown hCG $\beta$ induces EMT through TGF- $\beta$ receptor activation, further studies are required to characterize the mechanism underlying hCG $\beta$ and TGF- $\beta$ receptor interactions. In addition, other hCG $\beta$-activated receptors, such as the hCG/LH receptor, may also be important in CRC progression. Elucidation of these other hCG $\beta$ related pathways may lead to development of targeted therapeutic agents, such as TGF- $\beta$ antagonists, which are showing promise in the treatment of CRC. ${ }^{30}$

In conclusion, hCG $\beta$ expression by human CRC is associated with poor patient outcomes, and hCG $\beta$ may be a marker of aggressiveness because of its association with lymphatic invasion and lymph node metastasis. In selected patients, inhibition of hCG $\beta$ activity with hCG $\beta$ vaccine or TGF- $\beta$ antagonist may provide additional benefits in addition to current chemotherapy regimens.

\section{Acknowledgments}

We thank Drs. Kouichi Ishida and Aiman Elmansuri for technical assistance and the members of the Department of Cancer Pathology (Hokkaido University Graduate School of Medicine) for helpful discussions.

\section{Supplemental data}

Supplemental material for this article can be found at https://doi.org/10.1016/j.ajpath.2017.08.034.

\section{References}

1. Jemal A, Siegel R, Xu J, Ward E: Cancer statistics, 2010. Cancer J Clin 2010, 60:277-300
2. West NJ, Boustiere C, Fischbach W, Parente F, Leicester RJ: Colorectal cancer screening in Europe: differences in approach; similar barriers to overcome. Int J Colorectal Dis 2009, 24:731-740

3. Cole LA: hCG, the wonder of today's science. Reprod Biol Endocrinol 2012, 10:24

4. Pierce JG, Parsons TF: Glycoprotein hormones: structure and function. Annu Rev Biochem 1981, 50:465-495

5. Lundin M, Nordling S, Lundin J, Alfthan H, Stenman UH, Haglund C Tissue expression of human chorionic gonadotropin beta predicts outcome in colorectal cancer: a comparison with serum expression. Int J Cancer 2001, 95:18-22

6. Louhimo J, Kokkola A, Alfthan H, Stenman UH, Haglund C: Preoperative hCGbeta and CA 72-4 are prognostic factors in gastric cancer. Int J Cancer 2004, 111:929-933

7. Louhimo J, Alfthan H, Stenman UH, Haglund C: Serum HCG beta and CA 72-4 are stronger prognostic factors than CEA, CA 19-9 and CA 242 in pancreatic cancer. Oncology 2004, 66:126-131

8. Butler SA, Ikram MS, Mathieu S, Iles RK: The increase in bladder carcinoma cell population induced by the free beta subunit of human chorionic gonadotrophin is a result of an anti-apoptosis effect and not cell proliferation. Br J Cancer 2000, 82:1553-1556

9. Lapthorn AJ, Harris DC, Littlejohn A, Lustbader JW, Canfield RE, Machin KJ, Morgan FJ, Isaacs NW: Crystal structure of human chorionic gonadotropin. Nature 1994, 369:455-461

10. Sobin LH, Compton CC: TNM seventh edition: what's new, what's changed: communication from the International Union Against Cancer and the American Joint Committee on Cancer. Cancer 2010, 116: $5336-5339$

11. Louhimo J, Carpelan-Holmstrom M, Alfthan H, Stenman UH, Jarvinen HJ, Haglund C: Serum HCG beta, CA 72-4 and CEA are independent prognostic factors in colorectal cancer. Int J Cancer 2002, 101:545-548

12. Akagi T, Sasai K, Hanafusa H: Refractory nature of normal human diploid fibroblasts with respect to oncogene-mediated transformation. Proc Natl Acad Sci U S A 2003, 100:13567-13572

13. Itoh S, Taketomi A, Tanaka S, Harimoto N, Yamashita Y, Aishima S, Maeda T, Shirabe K, Shimada M, Maehara Y: Role of growth factor receptor bound protein 7 in hepatocellular carcinoma. Mol Cancer Res 2007, 5:667-673

14. Yamada T, Tsuda M, Ohba Y, Kawaguchi H, Totsuka Y, Shindoh M: PTHrP promotes malignancy of human oral cancer cell downstream of the EGFR signaling. Biochem Biophys Res Commun 2008, 368:575-581

15. Mahabir R, Tanino M, Elmansuri A, Wang L, Kimura $T$, Itoh $T$, Ohba Y, Nishihara H, Shirato H, Tsuda M, Tanaka S: Sustained elevation of Snail promotes glial-mesenchymal transition after irradiation in malignant glioma. Neuro Oncol 2014, 16:671-685

16. Elmansuri AZ, Tanino MA, Mahabir R, Wang L, Kimura T, Nishihara H, Kinoshita I, Dosaka-Akita H, Tsuda M, Tanaka S: Novel signaling collaboration between TGF-beta and adaptor protein Crk facilitates EMT in human lung cancer. Oncotarget 2016, 7:27094-27107

17. Eveno C, Broqueres-You D, Feron JG, Rampanou A, TijerasRaballand A, Ropert S, Leconte L, Levy BI, Pocard M: Netrin-4 delays colorectal cancer carcinomatosis by inhibiting tumor angiogenesis. Am J Pathol 2011, 178:1861-1869

18. Harmon RL, Sugarbaker PH: Prognostic indicators in peritoneal carcinomatosis from gastrointestinal cancer. Int Semin Surg Oncol 2005, 2:3

19. Yamaguchi A, Ishida T, Nishimura G, Kumaki T, Katoh M, Kosaka T, Yonemura Y, Miyazaki I: Human chorionic gonadotropin in colorectal cancer and its relationship to prognosis. Br J Cancer 1989, 60: $382-384$

20. Kido A, Mori M, Adachi Y, Yukaya H, Ishida T, Sugimachi K: Immunohistochemical expression of beta-human chorionic gonadotropin in colorectal carcinoma. Surg Today 1996, 26:966-970

21. Shousha S, Chappell R, Matthews J, Cooke T: Human chorionic gonadotrophin expression in colorectal adenocarcinoma. Dis Colon Rectum 1986, 29:558-560 
22. Carpelan-Holmstrom M, Louhimo J, Stenman UH, Alfthan H, Jarvinen H, Haglund C: CEA, CA 242, CA 19-9, CA 72-4 and hCGbeta in the diagnosis of recurrent colorectal cancer. Tumour Biol 2004, 25:228-234

23. Lundin M, Nordling S, Carpelan-Holmstrom M, Louhimo J, Alfthan H, Stenman UH, Haglund C: A comparison of serum and tissue hCG beta as prognostic markers in colorectal cancer. Anticancer Res 2000, 20:4949-4951

24. Moulton HM, Yoshihara PH, Mason DH, Iversen PL, Triozzi PL: Active specific immunotherapy with a beta-human chorionic gonadotropin peptide vaccine in patients with metastatic colorectal cancer: antibody response is associated with improved survival. Clin Cancer Res 2002, 8:2044-2051

25. Berndt S, Blacher S, Munaut C, Detilleux J, Perrier d'Hauterive S, Huhtaniemi I, Evain-Brion D, Noel A, Fournier T, Foidart JM: Hyperglycosylated human chorionic gonadotropin stimulates angiogenesis through TGF-beta receptor activation. FASEB J 2013, 27:1309-1321

26. Gulubova M, Manolova I, Ananiev J, Julianov A, Yovchev Y, Peeva K: Role of TGF-beta1, its receptor TGFbetaRII, and Smad proteins in the progression of colorectal cancer. Int J Colorectal Dis 2010, 25:591-599

27. Liu XQ, Rajput A, Geng L, Ongchin M, Chaudhuri A, Wang J: Restoration of transforming growth factor-beta receptor II expression in colon cancer cells with microsatellite instability increases metastatic potential in vivo. J Biol Chem 2011, 286:16082-16090

28. Lehnert SA, Akhurst RJ: Embryonic expression pattern of TGF beta type-1 RNA suggests both paracrine and autocrine mechanisms of action. Development 1988, 104:263-273

29. Fujii D, Brissenden JE, Derynck R, Francke U: Transforming growth factor beta gene maps to human chromosome 19 long arm and to mouse chromosome 7. Somat Cell Mol Genet 1986, 12: 281-288

30. Swallow CJ, Partridge EA, Macmillan JC, Tajirian T, DiGuglielmo GM, Hay K, Szweras M, Jahnen-Dechent W, Wrana JL, Redston M, Gallinger S, Dennis JW: alpha2HS-glycoprotein, an antagonist of transforming growth factor beta in vivo, inhibits intestinal tumor progression. Cancer Res 2004, 64:6402-6409 